\title{
ANALISIS KEPUASAN PELANGGAN KAFE WAROENG KOPI KAYUMAS
}

\author{
Alex Siswo Dwi Raharjo'), Sulistyaningsih'), Puryantoro $^{3^{*} \text { ) }}$ \\ Fakultas Pertanian, Universitas Abdurachman Saleh Situbondo \\ *Email Korespondensi : puryantorounars@gmail.com
}

\begin{abstract}
Abstrak
Tanaman kopi merupakan tanaman perkebunan yang memiliki nilai ekonomis yang sangat tinggi. Sejalan dengan itu peminat dan tren minum kopi di Situbondo kian meningkat. Seiring dengan meningkatnya minat konsumen terhadap minuman kopi membuat orang berlomba-lomba membuat tempat yang nyaman dalam menikmati kopi. Tujuan dari penelitian ini adalah (1). Menganalisis karakteristik pelanggan Waroeng Kopi Kayumas. (2). Menganalisis tingkat kepuasan pelanggan Waroeng Kopi Kayumas. Analisis statistik yang digunakan dalam penelitian ini adalah Analisis Deskriptif, Customer Satisfaction Index yang dilakukan kepada 30 responden. Hasil dari penelitian ini adalah rata-rata kosumen Waroeng Kopi Kayumas adalah mereka yang berusia 17-23 diamana usia ini masih tergolong usia sangat produktif. Hasil kepuasan pelanggan Waroeng Kopi Kayumas yang diukur menggunakan Customer Satisfaction Index sebesar 77,6\% diamana pelanggan merasa puas dengan tempat tersebut.
\end{abstract}

Kata kunci: Kafe Waroeng Kopi, Kepuasan Pelanggan, Kopi Kayumas

\begin{abstract}
The coffee plant is a plantation crop that has very high economic value. In line with this, the interest in and the trend of drinking coffee in Situbondo is increasing. Along with creating consumer interest in coffee drinks, people are competing in a comfortable place to enjoy coffee. The objectives of this study are (1). Analyzing comparing Waroeng Kopi Kayumas customers. (2). Analyzing the level of customer satisfaction at Waroeng Kopi Kayumas. The statistical analysis used in this research is Descriptive Analysis, the Customer Satisfaction Index which was conducted on 30 respondents. The results of this study are that the average consumer of Waroeng Kopi Kayumas is those aged 17-23 years who are still classified as very productive ages. The results of customer satisfaction at Waroeng Kopi Kayumas which are measured using a Customer Satisfaction Index of 77.6\% where the customer is satisfied with the place.
\end{abstract}

Keywords: Waroeng Kopi Cafe, Customer Satisfaction, Kayumas Coffee

\section{PENDAHULUAN}

Banyaknya produksi kopi di Indonesia membuat banyak perusahaan home Industri dan Kafe berlomba-lomba menciptakan berbagai macam olahan berbahan dasar kopi. Mulai dari makanan maupun minuman dapat di campurkan dengan bahan dasar kopi, misalnya makanan dengan berbahan kopi cookies, aneka olahan kue dan lain-lainnya. Sementara untuk olahan dengan berbahan dasar kopi dapat kita temui seperti kopi susu kekinian yang lagi booming saat ini, mocktail dan lain-lain.

Berkembangnya industri perkopian tak lain karena meningkatnya jumlah produksi kopi itu sendiri. Situbondo merupakan kabupaten penghasil kopi arabika dan robusta dengan rata-rata jumlah produksi pada tahun 2018 sebesar 537 Ton dalam bentuk Green Bean atau biji mentah, ini membuktikan bahwasanya kopi Kayumas sangat diminati oleh masyarakat luas baik masyarakat lokal dan mancanegara. Salah satu kafe yang tetap eksis menjual kopi kayumas adalah Kafe Waroeng Kopi Kayumas yang ada di Kecamatan Asembagus Kabupaten Situbondo. 
Kafe Waroeng Kopi Kayumas berdiri sejak tahun 2010 yang didirikan oleh Bapak Didik Suryadi yang bekerja sama sekaligus sekretaris di Kelompok Tani Sejahtera. Waroeng Kopi Kayumas didirikan lantaran kopi yang dihasilkan masyarakat Desa Kayumas memiliki potensi dan banyak diminati oleh masyarakat karena rasa dan aromanya yang nikmat. Dari situlah pemilik kafe berkeinginan mengenalkan serta mempromosikan kopi kayumas lebih luas. Tempat yang nyaman, harga terjangkau, kualitas yang baik mampu menarik pelanggan yang datang betah berlama-lama di Kafe Warowng Kopi Kayumas ini, karena kepuasan pelanggan menjadi prioritas di kafe ini.

Fenomena berkembangnya bisnis kuliner terjadi di kota-kota besar maupun kecil seperti Jakarta, Bandung, Surabaya bahkan Situbondo banyak sekali kedai kopi dengan berbagai konsep dan menu yang ditawarkan terutama di daerah perkantoran atau jalur utama. Semakin maraknya ragam kuliner yang disajikan dan semakin berkembangnya jumlah gerai yang menyajikan kuliner terutama minuman berbahan kopi di Situbondo, hal ini menjadikan daya tarik penulis untuk melakukan penelitian tentang bisnis kuliner yang difokuskan pada salah satu jenis kuliner yaitu coffee shop. Salah satunya adalah Waroeng Kopi Kayumas menyediakan beragam kopi yang berkualitas unggul, produk yang paling diandalkan di Waroeng Kopi Kayumas adalah minuman berbahan dasar kopi.

Namun tidak hanya kopi yang ditawarkan melainkan Waroeng Kopi Kayumas menyediakan makanan mulai dari appertize hingga dessert tempatnya nyaman untuk berkumpul dengan kerabat. Waroeng Kopi Kayumas memiliki kualitas pelayanan yang baik dan harga yang terjangkau. Dengan semakin meningkatnya persaingan yang ada, Waroeng Kopi Kayumas Situbondo terus melakukan pembenahan sarana prasarana, bahan baku dan sumber daya manusia. Hal ini dilakukan guna meningkatkan kepuasan pelanggan. Terciptanya kepuasan pelanggan diharapkan Waroeng Kopi Kayumas dapat bersaing dan unggul dibanding kompetitornya. Menurut Kotler dan Keller (2013) kepuasan adalah perasaan senang atau kecewa seseorang yang timbul karena membandingkan kinerja yang diperepsikan produk (atau hasil) terhadap ekspekasi mereka. Jika kinerja gagal memenuhi ekspektasi, pelanggan akan tidak puas. Jika kinerja melebihi ekspektasi, pelanggan akan puas, ketika pelanggan merasa puas tidak menutup kemungkinan untuk merekomendasikan produk tersebut. Kualitas pelayanan dan harga produk sering kali menjadi pertimbangan utama pelanggan dalam membeli dan menggunakan suatu produk.

Kemampuan perusahaan dalam memenuhi kebutuhan pelanggan itu sendiri sangat dipengaruhi oleh tingkat mutu yang diberikan perusahaan kepada pelanggan yaitu kualitas pelayanan. Semakin tinggi tingkat mutu pelayanan yang diberikan perusahaan kepada pelanggan, maka akan semakin tinggi tingkat terpenuhinya kebutuhan pelanggan yang biasa dinyatakan dengan tingkat kepuasan pelanggan. Harga merupakan salah satu faktor yang harus dikendalikan secara selaras dengan tujuan yang ingin dicapai oleh perusahaan.

Kondisi ini membuat pelanggan semakin leluasa dalam memilih jasa yang ditawarkan perusahaan -perushaan industri kuliner. Pelayanan yang mempunyai kualitas yang sama tetapi menetapkan harga yang relatif murah akan memberikan nilai lebih tinggi kepada pelanggannya. Adanya persaingan dapat menyebabkan dorongan bagi perusahaan untuk memaksimalkan strategi pemasaran yang diberikan, seperti contohnya kualitas pelayanan apakah sesuai dengan standar kenyamanan pelanggan dan apakah harga yang diberikan Waroeng Kopi Kayumas sesuai dengan rasa serta kualitas bahan baku yang diberikan. 


\section{METODE PENELITIAN}

Metode yang digunakan adalah metode deskriptif analisis yang memusatkan perhatian pada pemecahan masalah yang actual. Lokasi penelitian dipilih secara sengaja (purposive) yaitu Waroeng Kopi Kayumas Kecamatan Asembagus Kabupaten Kabupaten Situbondo. Metode pengambilan sampel pada penelitian ini menggunakan pendekatan non-probability sampling, yang setiap anggota populasi tidak menggunakankesempatan yang sama untuk dipilih. Metode non-probability sampling yang digunakan adalah teknik convenience sampling, dimana pemilihan anggota sampel dilakukan terhadap pelanggan yang kebetulan dijumpai di Waroeng Kopi Kayumas dan bersedia untuk dijadikan sebagai responden pada penelitian ini. Jika responden setuju untuk diwawancarai melalui bantuan kuesioner lalu diberi arahan untuk mengisi kuesioner dengan benar. Sampel yang diambil sebanyak 30 responden. Alat analisis yang digunakan dalam penelitian ini adalah analisis deskriptif dan Customer Satisfaction Index (CSI). Analisis deskriptif digunakan untuk mengetahui gambaran karakteristik umum pelanggan Waroeng Kopi Kayumas dan Customer Satisfaction Index (CSI) digunakan untuk mengetahui tingkat kepuasan pelanggan Waroeng Kopi Kayumas.

\section{HASIL DAN PEMBAHASAN}

Berdasarkan hasil analisis di peroleh nilai Customer Satisfaction Index adalah sebesar 83,4\%. Nilai Customer Satisfaction Index diperoleh dengan membagi nilai Weight Score total dengan skala maksimum yang digunakan, dalam penelitian ini menggunakan skala linkert (1-5). Setalah dibagi lima dikalikan dengan 100\%. Nilai Weight Score Total diperoleh dengan menjumlahkan seluruh hasil Weight Score dari masing-masing atribut Waroeng Kopi Kayumas. Dengan demikian, berdasarkan hasil Indeks kepuasan nilai Customer Satisfaction Index (CSI) Waroeng Kopi Kayumas berada pada rentang $80 \%<\mathrm{CSI} \leq$ $100 \%$.

Nilai maksimal dari Customer Satisfaction Index (CSI) adalah 100\%. Hal ini berarti masih ada kekurangan yang harus di perbaiki dari atribut Waroeng Kopi Kayumas sebesar $16,6 \%$.

Tabel 1. Hasil Customer Satisfaction Index

\begin{tabular}{|c|c|c|c|c|c|}
\hline Atribut & Kode & $\begin{array}{l}\text { Rataan Skor } \\
\text { Kepentingan }\end{array}$ & $\begin{array}{l}\text { Rataan } \\
\text { Skor } \\
\text { Kinerja }\end{array}$ & $\begin{array}{c}\text { Weight Factor } \\
(\%)\end{array}$ & $\begin{array}{l}\text { Weight } \\
\text { Skor }\end{array}$ \\
\hline Cita Rasa Makanan & A1 & 4.20 & 3.90 & 4.22 & 0.18 \\
\hline Cita Rasa Minuman & $\mathrm{A} 2$ & 4.30 & 3.90 & 4.32 & 0.19 \\
\hline Keragaman pilihan & A3 & 4.20 & 4.17 & 4.22 & 0.18 \\
\hline Harga Makanan & A4 & 3.80 & 3.30 & 3.82 & 0.15 \\
\hline Harga Minuman & A5 & 3.80 & 3.33 & 3.82 & 0.15 \\
\hline Lokasi & A6 & 4.47 & 4.37 & 4.49 & 0.20 \\
\hline $\begin{array}{l}\text { Kesungguhan dalam } \\
\text { menyelesaikan } \\
\text { masalah }\end{array}$ & A7 & 4.13 & 3.93 & 4.16 & 0.17 \\
\hline Keramahan Pramusaji & A8 & 4.17 & 3.80 & 4.19 & 0.18 \\
\hline $\begin{array}{l}\text { Menjaga Hubungan } \\
\text { Dengan Pelanggan }\end{array}$ & A9 & 4.13 & 3.93 & 4.16 & 0.17 \\
\hline Perhatian Pramusaji & A10 & 4.17 & 3.77 & 4.19 & 0.18 \\
\hline Penampilan Pramusaji & A11 & 4.13 & 3.77 & 4.16 & 0.17 \\
\hline Jam Buka & $\mathrm{A} 12$ & 4.07 & 4.60 & 4.09 & 0.17 \\
\hline
\end{tabular}




\begin{tabular}{|c|c|c|c|c|c|}
\hline Kecepatan Pelayanan & A13 & 4.20 & 4.20 & 4.22 & 0.18 \\
\hline $\begin{array}{l}\text { Ketanggapan } \\
\text { Pelayanan }\end{array}$ & A14 & 4.20 & 4.07 & 4.22 & 0.18 \\
\hline Kecepatan transaksi & A15 & 4.00 & 3.43 & 4.02 & 0.16 \\
\hline Kenyamanan Ruangan & A16 & 4.37 & 3.97 & 4.39 & 0.19 \\
\hline Kebersihan Ruangan & A17 & 4.40 & 4.00 & 4.43 & 0.20 \\
\hline $\begin{array}{l}\text { Kebersihan Peralatan } \\
\text { Makanan }\end{array}$ & A18 & 4.33 & 4.03 & 4.36 & 0.19 \\
\hline Penataan Ruangan & A19 & 3.97 & 3.87 & 3.99 & 0.16 \\
\hline $\begin{array}{l}\text { Ketersediaan } \quad \text { Area } \\
\text { Parkir }\end{array}$ & $\mathrm{A} 20$ & 3.83 & 3.07 & 3.86 & 0.15 \\
\hline Kebersihan Toilet & A21 & 3.97 & 3.93 & 3.99 & 0.16 \\
\hline Papan Nama & A22 & 4.13 & 4.07 & 4.16 & 0.17 \\
\hline Sosial Media & A23 & 4.17 & 3.40 & 4.19 & 0.18 \\
\hline Pelayanan & A24 & 4.30 & 4.07 & 4.32 & 0.19 \\
\hline Jumlah & & 99.43 & 92.87 & 100.00 & 4.17 \\
\hline Rata-rata & & 4.14 & 3.87 & & \\
\hline \multicolumn{6}{|c|}{ Customer Satisfactions Index(CSI) $(4.17 / 5) \times 100 \%=83.4 \%$} \\
\hline
\end{tabular}

Sumber : Data Primer Diolah, 2020.

Sesuai dengan hasil penelitian yang didapat berdasarkan hasil penelitian Analisis Customer Satisfaction Index yang dilakukan untuk melihat perhitungan indeks kepuasan pelanggan Kafe Waroeng Kopi Kayumas yang telah dilakukan kepada 30 responden pelanggan Waroeng Kopi Kayumas melalui penyebaran kuesioner untuk mendapatkan kecenderungan jawaban responden terhadap masing-masing atribut. Berdasarkan hasil analisis diperoleh nilai Customer Satisfaction Index adalah sebesar 83,4\% yang menginterpretasikan bahwa pelanggan Waroeng Kopi Kayumas merasa sangat puas dengan produk dan pelayanan di Kafe Waroeng Kopi Kayumas. Penelitian ini juga selaras dengan hasil penelitian Torey, J. R., \& Lolowang, T. F. (2016) proses pengukuran tingkat kepuasan konsumen dari segi produk kopi dan pelayanan mencapai total skor pengambilan data 2.090 yang menunjukan angka indeks pengukuran kepuasan konsumen sebesar $83.6 \%$ dan tergolong sangat puas.

Artibut lokasi dan kebersihan lingkungan di waroeng kopi kayu mas mendapatkan tingkat kepuasan tertinggi dari konsumen. Berbeda dengan hasil penelitian Ranitaswari, P. A., Mulyani, S., \& Sadyasmara, C. A. B. (2018) atribut dengan tingkat kepuasan atau tingkat kesesuaian tertinggi di Geo Coffee adalah kecepatan dalam merespon keluhan dan permasalahan pelanggan dengan tingkat kesesuaian sebesar 120,34\% yang berarti kinerja Geo Coffee melebihi kepentingan konsumen. Atribut dengan tingkat kesesuaian terendah adalah Pelayan menangani konsumen sesuai kebutuhan dengan tingkat kesesuaian sebesar 80,05\% yang berarti kinerja Geo Coffee perlu diperbaiki karena belum memenuhi keinginan konsumen.

Sementara itu menurut hasil penelitian Winarno, S., Mananeke, L., \& Ogi, I. W. (2018) pelayanan konsumen dan fasilitas secara simultan dan parsial memiliki pengaruh terhadap keberhasilan dan kegagalan pada Kepuasan Konsumen, sehingga kafe waroeng kayu mas perlu meningkatkan pelayanan dan fasilitas agar kepuasan konsumen menjadi lebih maksimal. 


\section{KESIMPULAN}

Berdasarkan hasil analisis Customer Satisfaction Index menghasilkan nilai 83,4\% yang menunjukan bahwa secara keseluruhan pelanggan sangat puas terhadap produk dan pelayanan yang ada di Kafe Waroeng Kopi Kayumas.

\section{REFERENSI}

Kotler, Philip., Keller, Kevin L. (2013). Manajemen Pemasaran, Jilid Kedua, Jakarta: Erlangga.

Ranitaswari, P. A., Mulyani, S., \& Sadyasmara, C. A. B. (2018). Analisis Kepuasan Konsumen Terhadap Kualitas Produk Kopi Dan Kualitas Pelayanan Menggunakan Metode Importance Perfomance Analysis (Studi Kasus Di Geo Coffee). Jurnal Rekayasa dan Manajemen Agroindustri, 6(2), 147-157.

Torey, J. R., \& Lolowang, T. F. (2016). Analisis Tingkat Kepuasan Konsumen Terhadap Produk Kopi Dan Pelayanan Di Rumah Kopi Billy Cabang Megamas Manado. AGRISOSIOEKONOMI, 12(3A), 11-26.

Winarno, S., Mananeke, L., \& Ogi, I. W. (2018). ANALISIS PELAYANAN KONSUMEN DAN FASILITAS TERHADAP KEPUASAN KONSUMEN KEDAI KOPI MAXX COFFEE CABANG HOTEL ARYADUTA MANADO. Jurnal EMBA: Jurnal Riset Ekonomi, Manajemen, Bisnis dan Akuntansi, 6(3). 